\title{
A novel locus for autosomal dominant nonsyndromic hearing loss, DFNA50, maps to chromosome 7q32 between the DFNB17 and DFNB13 deafness loci
}

\author{
S Modamio-Høybjør, M A Moreno-Pelayo, A Mencía, I del Castillo, S Chardenoux, D Morais, \\ M Lathrop, C Petit, F Moreno
}

J Med Genet 2004;41:e14 (http://www.jmedgenet.com/cgi/content/full/41/2/e14). doi: 10.1136/jmg.2003.012500

$\mathrm{P}$ rogressive hearing loss is a significant problem in all ageing populations. By the age of 80 years, nearly $50 \%$ of individuals have hearing loss that impairs their ability to communicate easily, leading to increasing social isolation. Progressive hearing loss in middle and late adulthood is considered multifactorial, with involvement of both genetic and environmental factors. ${ }^{2}$ In contrast, childhood or adolescent hearing loss is often inherited as an autosomal dominant Mendelian trait, representing about $20 \%$ of all cases of hereditary nonsyndromic sensorineural hearing impairment (NSSHI). Postlingual inherited deafness is usually moderate to severe and progressive, and it often affects a particular range of frequencies. ${ }^{3}$

Hereditary deafness has proved extremely heterogeneous genetically; more than 40 loci have been mapped for autosomal dominant (AD) NSSHI, and 17 deafness genes from these loci have been identified to date. ${ }^{4}$ Linkage analysis using large pedigrees is a useful tool for mapping and identifying novel deafness genes, a key step for improving our current understanding of auditory function. Here we describe the localisation of a novel DFNA locus on chromosome 7q32, involving the study of a Spanish family with postlingual and progressive hearing loss affecting all frequencies.

\section{PATIENTS AND METHODS}

Family data

A five generation family (S403) with a history of ADNSSHI was identified through the Hospital Universitario de Valladolid, Spain. The pedigree consisted of 74 members, 37 of whom were affected (fig 1). Appropriate informed consent was obtained from all participants of the study and from parents of subjects younger than 18 years. Clinical evaluation was carried out, blood samples were collected from 55 family members, and DNA was extracted by standard techniques. Environmental factors were excluded as causes of hearing impairment. No syndromic features were present. Tympanometry with acoustic reflex testing indicated proper functioning of the middle ear, and pure tone audiometry was performed to test for air conduction $(250-8000 \mathrm{~Hz})$ and bone conduction (250-4000 Hz). Previous audiograms were obtained where possible.

\section{Genotyping and linkage analysis}

A genome wide screening was performed with 394 microsatellite markers distributed with an average spacing of 10 cM (ABI Prism Linkage Mapping Set 2, Applied Biosystems, Foster City, CA, USA). Markers for the exclusion of all known DFNA loci and for fine mapping of the critical interval were taken from the Généthon human linkage map ${ }^{5}$ and from the Marshfield chromosome 7 map (http://research. marshfieldclinic.org/genetics). An additional short tandem repeat (STR) in the DFNA50 critical interval was identified by

\section{Key Points}

- Nonsyndromic sensorineural hearing impairment (NSSHI) is the most common form of genetic deafness. Approximately $20 \%$ of cases segregate as autosomal dominant (AD) traits, for which about 40 DFNA loci have been mapped and 17 genes have been identified, making ADNSSHI an extremely heterogeneous disorder.

- In this study, we report the mapping of a novel autosomal dominant deafness locus on $7 q 32$, DFNA50, by studying a large multigenerational Spanish family segregating postlingual and progressive ADNSSH affecting all frequencies. A maximum LOD score of 10.66 at $\theta=0$ was obtained for marker D7S530. The analysis of recombinant haplotypes located DFNA50 within a $3.8 \mathrm{cM}$ region delimited by markers D7S1875 and D7S2519.

- Four deafness loci (DFNB14, DFNB4, DFNB17, and DFNB13) were previously mapped to chromosome $7 q$, but their genetic intervals do not overlap with that of DFNA50, which is located $3.8 \mathrm{cM}$ distal to DFNB17 and $13.7 \mathrm{cM}$ proximal to DFNB13.

- Sequencing of two candidate genes, $\mathrm{SMOH}$ and UBE2H, within the DFNA50 interval did not reveal the cause of deafness in this family.

inspection of publicly available sequence data (NCBI, http://www.ncbi.nlm.nih.gov). Flanking primers were designed for PCR amplification of this STR. The amplicon was confirmed as a polymorphic microsatellite marker and deposited into the GDB database (http://www.gdb.org), being assigned the number D7S3304 (GDB:11511396). The order of markers used in this work was established by integrating genetic and physical maps (NCBI, http:// www.ncbi.nlm.nih.gov).

Fluorescently labelled alleles were analysed in an ABI PRISM 310 automated DNA sequencer (Applied Biosystems). Linkage analysis was performed using the LINKAGE 5.1 software package. ${ }^{6}$ Two point LOD scores between the deafness locus and each marker were calculated under a

Abbreviations: NSSHI, non-syndromic sensorineural hearing impairment; $A D$, autosomal dominant; STR, short tandem repeat 


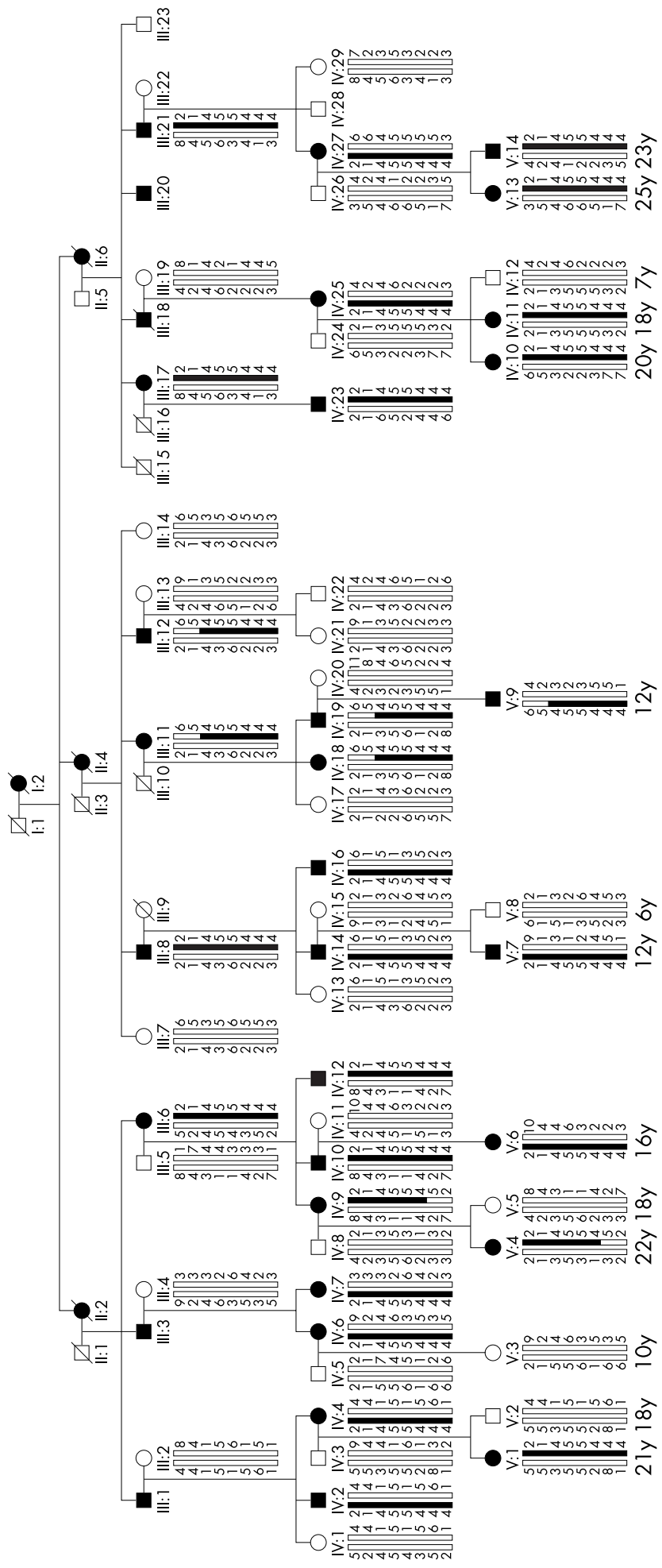

Figure 1 Pedigree and haplotype analysis of the Spanish family S403. Black symbols represent affected subjects. Haplotypes are represented by bars, with the haplotype associated with the hearing loss in black. The ages of youngest individuals are indicated below the haplotype.

fully penetrant autosomal dominant mode of inheritance, setting the disease allele frequency to 0.00001 and considering marker allele frequencies equal to each other.

\section{DNA sequencing analysis}

Primers were designed for the amplification of coding regions and exon intron boundaries of the SMOH (MIM 601500) and 
UBE2H (MIM 601082) genes. PCR was performed by standard procedures as previously described. ${ }^{7}$ Heteroduplex analysis was carried out in MDE gels (BioWhittaker, Rockland, ME, USA) according to the manufacturer's protocol. Sequences of PCR products were analysed in an automated DNA sequencer ABI PRISM 310 (Applied Biosystems).

\section{RESULTS AND DISCUSSION \\ Clinical features}

Affected family members showed a bilateral, symmetrical, progressive NSSHI. The earliest clinical evidence of hearing loss in the family was obtained for subjects V:7 and V:9, at the age of 12 years. Initially the hearing loss was mild, affecting all frequencies, but it later progressed to severe or profound in the seventh decade (fig 2). Linear regression analysis, based on all available audiograms of affected subjects, showed a $1.2 \mathrm{~dB} /$ year age linked progression of the hearing loss at all frequencies (data not shown). No evidence of vestibular dysfunction was found in affected subjects. Patient III:12 referred to episodes of bilateral tinnitus.

\section{Linkage analysis}

For linkage analysis, 52 members of the family were considered informative. Subjects V:3, V:8, and V:12 were only 10,6 , and 7 years old, respectively, below the age of onset of the hearing loss in the family, and therefore they were not included.

Initially, we tested the family for linkage to all described loci responsible for ADNSSHI, using the markers listed in the Hereditary Hearing Loss Homepage in each case. ${ }^{4}$ In all cases negative results were obtained, indicating the involvement of a novel locus responsible for the hearing loss in this family. Therefore, a genome wide scan was performed to map the deafness locus, using a set of 394 microsatellite markers with an average spacing of $10 \mathrm{cM}$. Significant linkage was found only to marker D7S530 (maximum two point LOD score of 10.66 at $\theta=0$ ) on chromosome $7 \mathrm{q} 32$ (fig 3). To confirm linkage, the family was then genotyped for markers flanking D7S530. Significant LOD scores at $\theta=0$ were found for markers D7S3304, D7S461, and D7S2544 (table 1). Extensive alterations of the disease gene frequency or the allele frequencies of microsatellite markers did not change the conclusions of the analysis. The position of the novel deafness locus, DFNA50, was delimited by analysis of the

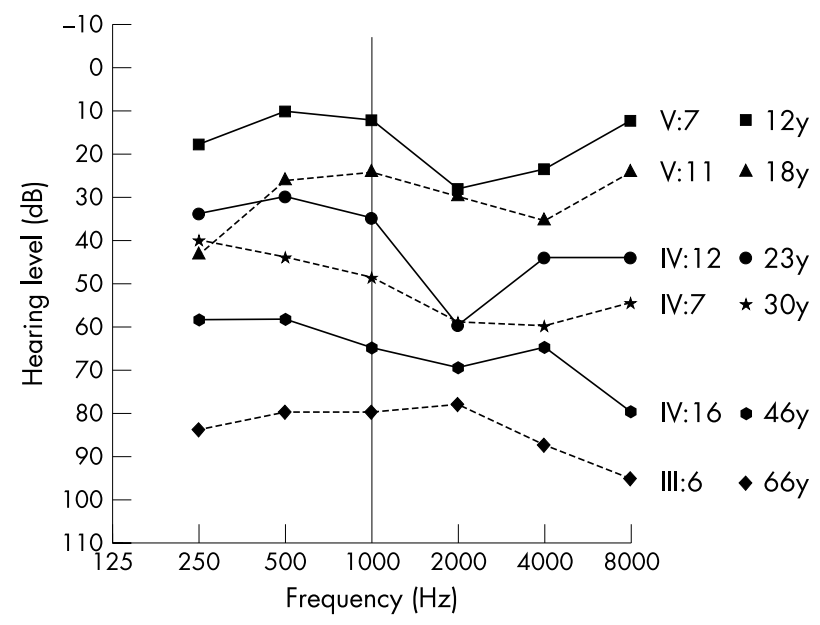

Figure 2 Audiograms showing the air conduction values obtained from six different affected subjects. Each graph point represents the average hearing loss for the right and left ears. recombinant haplotypes in subjects III:11, III:12, and IV:9. This analysis placed DFNA50 between the proximal marker D7S1875 and the distal marker D7S2519, which define a critical interval of $3.8 \mathrm{cM}$ (figs 1 and 3 ).

Four recessive loci for hearing impairment, DFNB14, ${ }^{8}$ DFNB4, ${ }^{9-11}$ DFNB 17, ${ }^{12}$ and DFNB $13^{13}$ map to chromosome 7q. As shown in fig 3, the DFNA50 critical interval does not overlap with those from the previously mapped loci, and it is localised $3.8 \mathrm{cM}$ distal to DFNB17 and $13.7 \mathrm{cM}$ proximal to DFNB13.

\section{Candidate gene analysis}

No genes for syndromic deafness are located within the DFNA50 critical interval. The human chromosome region containing DFNA50 shares conserved synteny with a segment of mouse chromosome 6, but no mutation causing hearing impairment in mice has been mapped to this region. This interval spans a physical distance of about $2.2 \mathrm{Mb}$, and includes 21 known genes and a series of predicted or poorly characterised genes according to the annotation in the NCBI database (http://www.ncbi.nlm.nih.gov/mapview/). Using a candidate gene approach, UBE2H (MIM 601082) and SMOH (MIM 601500) were selected for our screening of mutations (fig 3).

$\mathrm{UBE} 2 \mathrm{H}$ is expressed in human cochlea (Unigene cluster, Hs.372758) and consists of 7 exons. ${ }^{14}$ It encodes the ubiquitin conjugating enzyme E2H. This class of enzymes is involved in a major pathway for protein degradation in eukaryotes, by catalysing the covalent attachment of ubiquitin to defined lysine residues of proteolytic substrates. This forms ubiquitin protein conjugates that are degraded by the 26S proteasome. Ubiquitin conjugation is highly selective and is required for a variety of cellular functions, such as DNA repair, cell cycle progression, and heat shock resistance. ${ }^{15-17}$ The E2H enzyme is capable of ubiquitinating histones in the laboratory. ${ }^{14}$ Although the functional role of $\mathrm{E} 2 \mathrm{H}$ in the cochlea remains uncertain, functional alteration of the ubiquitin pathway has been implicated in the aetiology of neurodegeneration. ${ }^{18}$ Furthermore, expression of UBE3B, another member of the ubiquitin ligase family, is highly induced immediately after noise trauma in the chick basilar papilla. ${ }^{19}$

It has been reported that $\mathrm{SMOH}$, a human homologue of the Drosophila Smo gene, is expressed in the cochlea (Unigene cluster, Hs.197366). This gene, consisting of 12 exons, ${ }^{20}$ encodes the transmembrane protein smoothened (Smo) that mediates the cellular response to the Hedgehog signalling molecule, a key agent in patterning numerous types of tissues. ${ }^{21}$ It has been documented that Hedgehog signalling is required for the correct morphogenesis of the inner ear, a complex process where inductive signals are necessary to transform the simple otic placode into the auditory and vestibular components of the inner ear. ${ }^{22-24}$

Screening for mutations in these two genes was performed by heteroduplex analysis and DNA sequencing of the exons and flanking regions in the affected subject III:8. This analysis only revealed three silent polymorphic changes in the $\mathrm{SMOH}$ open reading frame: $1137 \mathrm{G}>\mathrm{A}$ in exon 5; $1164 \mathrm{C}>\mathrm{G}$ in exon 6 (NCBI SNP cluster id: rs2703092); and $1722 \mathrm{~T}>\mathrm{C}$ in exon 10 (NCBI SNP cluster id: rs2016607).

Mapping of the novel DFNA50 locus further confirms the great genetic heterogeneity underlying the autosomal dominant forms of hereditary deafness. Reports of more families with hearing impairment linked to this novel locus should contribute to the identification of the responsible gene, providing insights into the auditory function and the molecular pathophysiology of age related hearing loss. 


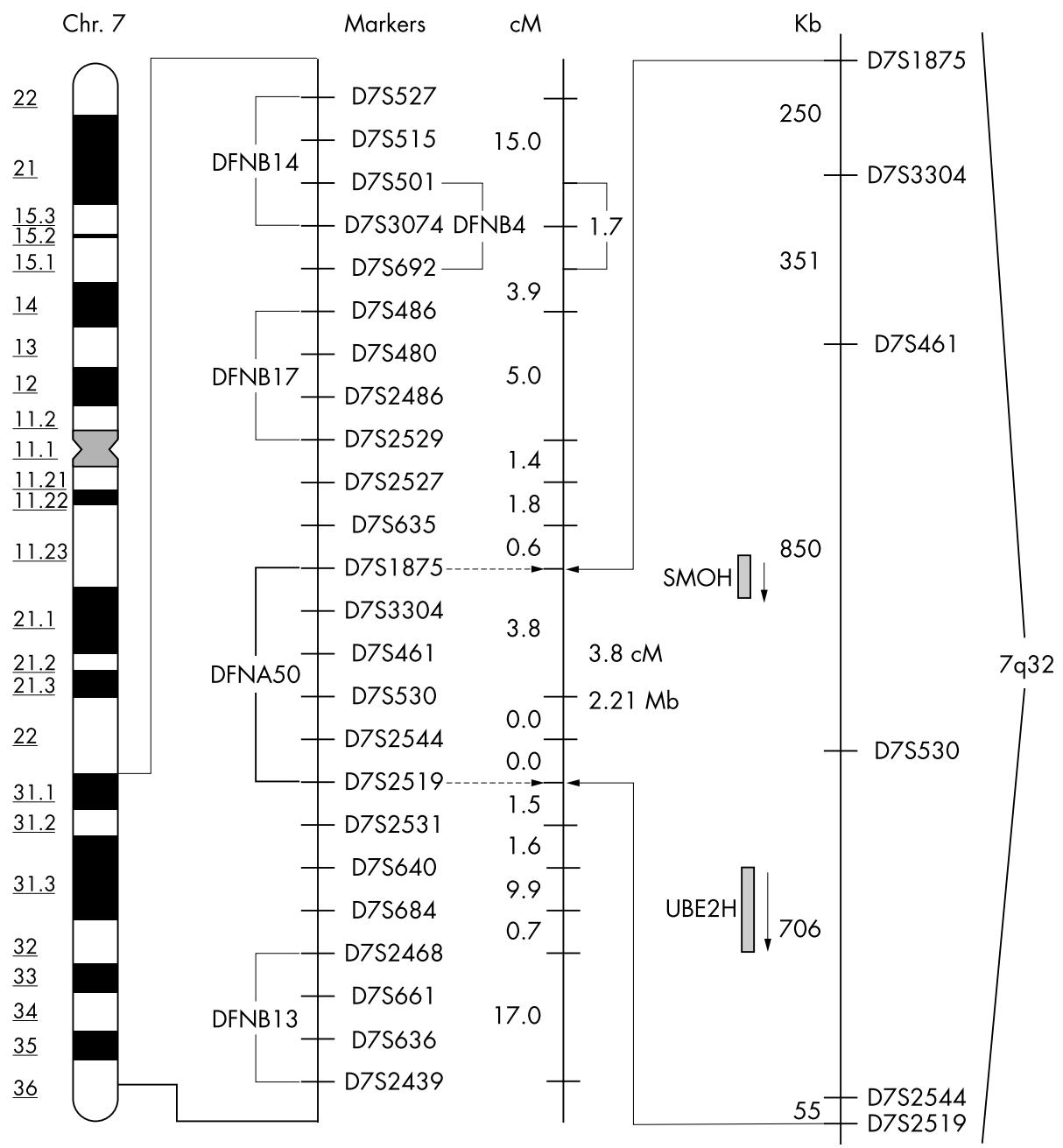

Figure 3 Physical and genetic maps of the 7q31-36 chromosomal region showing the localisation of DFNA50 and DFNB14, DFNB4, DFNB17, and DFNB13 critical intervals. cM, centimorgan; $M b$, megabase; $\mathrm{Kb}$, kilobase; $\mathrm{SMOH}$, (MIM 601500); and UBE2H, (MIM 601082). For clarity, the genetic and physical distances are not represented to scale.

Table 1 Two point LOD scores between 7q microsatellite markers and DFNA50

Recombination fractions $(\theta)$ :

\begin{tabular}{|c|c|c|c|c|c|c|c|c|c|}
\hline Marker & 0.00 & 0.01 & 0.05 & 0.10 & 0.20 & 0.30 & 0.40 & $Z_{\max }$ & $\theta_{\max }$ \\
\hline D7S515 & $-\infty$ & -0.64 & 2.33 & 3.16 & 3.23 & 2.52 & 1.40 & 3.34 & 0.15 \\
\hline D7S486 & $-\infty$ & 0.22 & 2.51 & 3.09 & 2.97 & 2.23 & 1.14 & 3.16 & 0.13 \\
\hline D7S480 & $-\infty$ & 4.72 & 5.49 & 5.28 & 4.16 & 2.67 & 1.16 & 5.49 & 0.06 \\
\hline D7S2486 & $-\infty$ & 2.42 & 3.97 & 4.16 & 3.54 & 2.43 & 1.13 & 4.17 & 0.09 \\
\hline D7S2527 & $-\infty$ & 5.34 & 6.08 & 5.83 & 4.62 & 3.04 & 1.34 & 6.08 & 0.05 \\
\hline D7S635 & $-\infty$ & 6.22 & 6.92 & 6.61 & 5.25 & 3.49 & 1.64 & 6.92 & 0.05 \\
\hline D7S1875 & $-\infty$ & 5.67 & 6.39 & 6.12 & 4.84 & 3.20 & 1.50 & 6.39 & 0.05 \\
\hline D7S3304 & 5.04 & 4.94 & 4.54 & 4.02 & 2.94 & 1.87 & 0.88 & 5.04 & 0.00 \\
\hline D7S461 & 6.08 & 5.98 & 5.58 & 5.05 & 3.93 & 2.72 & 1.41 & 6.08 & 0.00 \\
\hline D7S530 & 10.66 & 10.48 & 9.75 & 8.81 & 6.78 & 4.55 & 2.17 & 10.66 & 0.00 \\
\hline D7S2544 & 9.60 & 9.44 & 8.79 & 7.93 & 6.11 & 4.12 & 1.98 & 9.60 & 0.00 \\
\hline D7S2519 & $-\infty$ & 9.09 & 9.02 & 8.32 & 6.47 & 4.31 & 1.98 & 9.20 & 0.02 \\
\hline D7S2531 & $-\infty$ & 9.27 & 9.20 & 8.50 & 6.64 & 4.45 & 2.07 & 9.38 & 0.02 \\
\hline D7S640 & $-\infty$ & 7.29 & 7.97 & 7.63 & 6.19 & 4.29 & 2.07 & 7.97 & 0.05 \\
\hline D7S684 & $-\infty$ & 3.27 & 4.20 & 4.18 & 3.47 & 2.39 & 1.13 & 4.25 & 0.07 \\
\hline D7S661 & $-\infty$ & 0.73 & 3.59 & 4.27 & 3.98 & 2.89 & 1.35 & 4.32 & 0.13 \\
\hline D7S636 & $-\infty$ & -6.78 & -1.05 & 0.93 & 2.08 & 1.97 & 1.22 & 2.14 & 0.23 \\
\hline
\end{tabular}

Markers used for the fine mapping analysis are in bold.

\section{ACKNOWLEDGEMENTS}

We thank members of the Spanish family, whose participation made this study possible. This work was supported by grants from the
Comisión Interministerial de Ciencia y Tecnología CICYT-SAF 990025, the Ministerio de Ciencia y Tecnología SAF 2002-03966, and the European Comunity QLG2-CT-1999-0098. 


\section{Authors' affiliations}

S Modamio-Høybjør*, M A Moreno-Pelayo*, A Mencía, I del Castillo, F Moreno, Unidad de Genética Molecular, Hospital Ramón y Cajal, Madrid, Spain

S Chardenoux, C Petit, Unité de Génétique des Déficits Sensoriels, CNRS URA 1968, Institut Pasteur, Paris, France

D Morais, Servicio de Otorrhinolaringología, Hospital Universitario, Valladolid, Spain

M Lathrop, Centre National de Génotypage, Evry, France

*These authors contributed equally to this work and the order of authorship is arbitrary.

SMH and AM were fellows at the Ministerio de Ciencia y Tecnología and Fondo de Investigaciones Sanitarias, respectively.

Correspondence to: Dr F Moreno, Unidad de Genética Molecular Hospital Ramón y Cajal, Carretera de Colmenar Km 9, 28034, Madrid, Spain; fmoreno.hrc@salud.madrid.org

Accepted 18 August 2003

\section{REFERENCES}

1 Morton NE. Genetic epidemiology of hearing impairment. Ann N Y Acad Sci 1991:630:16-31.

2 Schuknecht HF, Gacek MR. Cochlear pathology in presbycusis. Ann Otol Rhinol Laryngol 1993;102:1-16.

3 Bom SJ, Kunst HP, Huygen PL, Cremers FP, Cremers CW. Non-syndromal autosomal dominant hearing impairment: ongoing phenotypical characterization of genotypes. British Journal of Audiology 1999;33:335-48

4 Van Camp G, Smith RJH. Hereditary Hearing Loss Homepage July 2003. http://dnalab-www.via.ac.be/dnalab/hhh.

5 Dib C, Faure S, Fizames C, Samson D, Drouot N, Vignal A, Millasseau P, Marc S, Hazan J, Seboun E, Lathrop M, Gyapay G, Morissette J, Weissenbach J. A comprehensive genetic map of the human genome based on 5,264 microsatellites. Nature 1996;380:152-4.

6 Lathrop GM, Lalouel JM, Julier C, Ott J. Multilocus linkage analysis in humans: detection of linkage and estimation of recombination. Am J Hum Genet 1985;37:482-98

7 del Castillo I, Villamar M, Moreno-Pelayo MA, del Castillo FJ, Alvarez A, Telleria D, Menéndez I, Moreno F. A deletion involving the connexin 30 gen in nonsyndromic hearing impairment. N Engl J Med 2002;346:243-9.

8 Mustapha M, Salem N, Weil D, el-Zir E, Loiselet J, Petit C. Identification of a locus on chromosome 7q31, DFNB14, responsible for prelingual sensorineural non-syndromic deafness. Eur J Hum Genet 1998;6:548-51
9 Baldwin CT, Weiss S, Farrer LA, De Stefano AL, Adair R, Franklyn B, Kidd KK, Korostishevsky M, Bonne-Tamir B. Linkage of congenital, recessive deafness (DFNB4) to chromosome 7q31 and evidence for genetic heterogeneity in the Middle Eastern Druze population. Hum Mol Genet 1995;4:1637-42.

10 Coucke P, Van Camp G, Demirhan O, Kabakkaya Y, Balemans W, Van Hauwe P, Van Agtmael T, Smith RJ, Parving A, Bolder CH, Cremers CW, Willems PJ. The gene for Pendred syndrome is located between D7S501 and D7S692 in a 1.7-cM region on chromosome 7q. Genomics 1997:40:48-54.

11 Li XC, Everett LA, Lalwani AK, Desmukh D, Friedman TB, Green ED, Wilcox ER. A mutation in PDS causes non-syndromic recessive deafness. Nat Genet 1998;18:215-17

12 Greinwald Jr JH, Wayne S, Chen AH, Scott DA, Zbar RI, Kraft ML, Prasad S, Ramesh A, Coucke P, Srisailapathy CR, Lovett M, Van Camp G, Smith RJ. Localisation of a novel gene for nonsyndromic hearing loss (DFNB17) to chromosome region 7q31. Am J Med Genet 1998;78:107-13.

13 Mustapha M, Chardenoux S, Nieder A, Salem N, Weissenbach J, el Zir E, Loiselet J, Petit C. A sensorineural progressive autosomal recessive form of isolated deafness, DFNB13, maps to chromosome 7q34-q36. Eur J Hum Genet 1998;6:245-50.

14 Kaiser P, Seufert W, Hofferer L, Kofler B, Sachsenmaier C, Herzog H, Jentsch S, Schweiger M, Schneider R. A human ubiquitin-conjugating enzyme homologous to yeast UBC8. J Biol Chem 1994;269:8797-802.

15 Finley D, Chau V. Ubiquitination. Annu Rev Cell Biol 1991;7:25-69

16 Hershko A, Ciechanover A. The ubiquitin system for protein degradation. Annu Rev Biochem 1992;61:761-807.

17 Jentsch S. The ubiquitin-conjugation system. Annu Rev Genet 1992;26:179-207.

18 Saigoh K, Wang YL, Suh JG, Yamanishi T, Sakai Y, Kiyosawa H, Harada T, Ichihara N, Wakana S, Kikuchi T, Wada K. Intragenic deletion in the gene encoding ubiquitin carboxi-terminal hydrolase in gad mice. Nat Genet 1999;23:47-51.

19 Lomax MI, Huang L, Cho Y, Gong TL, Altschuler RA. Differential display and gene arrays to examine auditory plasticity. Hear Res 2000;147:293-302.

20 Xie J, Murone M, Luoh SM, Ryan A, Gu Q, Zhang C, Bonifas JM, Lam CW, Hynes M, Goddard A, Rosenthal A, Epstein EH Jr, de Sauvage FJ. Activating Smoothened mutations in sporadic basal-cell carcinoma. Nature 1998:391:90-2.

21 Nybakken K, Perrimon N. Hedgehog signal transduction: recent finding. Curr Opin Genet Dev 2002;12:503-11.

22 Hammond KL, Loynes HE, Folarin AA, Smith J, Whiffield TT. Hedgehog signalling is required for correct anteroposterior patterning of the zebrafish otic vesicle. Development 2003;130:1403-17.

23 Riccomagno MM, Martinu L, Mulheisen M, Wu DK, Epstein DJ. Specification of the mammalian cochlea is dependent on Sonic Hedgehog. Genes Dev 2002;16:2365-78

24 Liu W, Li G, Chien JS, Raft S, Zhang H, Chiang C, Frenz DA. Sonic Hedgehog regulates otic capsule chondrogenesis and inner ear development in the mouse embryo. Dev Biol 2002;248:240-50. 